\title{
Erratum to: Performing Political Theory
}

Erratum to:

J. Uhr, Performing Political Theory, https://doi.org/10.1007/978-981-10-7998-6

In the original version of the book, the belated corrections from author in Frontmatter, Chapters 1, 2, 3, 4, 6 and 7 have been incorporated. The erratum book has been updated with the changes.

The updated online version of this book can be found at https://doi.org/10.1007/978-981-10-7998-6_1 https://doi.org/10.1007/978-981-10-7998-6_2 https://doi.org/10.1007/978-981-10-7998-6_3 https://doi.org/10.1007/978-981-10-7998-6_4 https://doi.org/10.1007/978-981-10-7998-6_6 https://doi.org/10.1007/978-981-10-7998-6_7 https://doi.org/10.1007/978-981-10-7998-6

(C) The Author(s) 2018 